\title{
North Pacific subtropical sea surface temperature frontogenesis and its connection with the atmosphere above
}

\author{
Leying Zhang ${ }^{1,2}$, Haiming $\mathrm{Xu}^{1}$, Jing $\mathrm{Ma}^{1}$, Ning Shi ${ }^{1}$, and Jiechun Deng ${ }^{1,3}$ \\ ${ }^{1}$ Collaborative Innovation Center on Forecast and Evaluation of Meteorological Disasters (CIC-FEMD), \\ Key Laboratory of Meteorological Disaster, Ministry of Education (KLME), Joint International \\ Research Laboratory of Climate and Environment Change (ILCEC), Nanjing University \\ of Information Science \& Technology, Nanjing 210044, China \\ ${ }^{2}$ Joint Innovation Center for Modern Forestry Studies, College of Biology and Environment, \\ Nanjing Forestry University, Nanjing 210037, China \\ ${ }^{3}$ Department of Atmospheric and Environmental Science, University at Albany, \\ State University of New York, Albany, NY 12222, USA
}

Correspondence: Leying Zhang (zhangleyingzi@126.com)

Received: 14 July 2018 - Discussion started: 17 July 2018

Revised: 1 February 2019 - Accepted: 1 April 2019 - Published: 24 April 2019

\begin{abstract}
The net heat flux and meridional temperature advection in the ocean are two factors in the North Pacific subtropical sea surface temperature front (NPSTF) frontogenesis occurring from October to the following February. However, the relative importance of these two factors has been rarely explored. In this study, frontogenesis of the NPSTF is examined quantitatively based on the mixed-layer heat budget equation to clarify the relative importance of net heat flux and meridional temperature advection and to further explore its connection with the atmosphere above. Diagnosis results show that the net heat flux dominates the frontogenesis from October to December, while the meridional temperature advection in the ocean contributes equally as or even more than the net heat flux in January and February. The atmosphere is critical to the frontogenesis of the NPSTF, including the direct effect of the net heat flux and the indirect effect through the Aleutian low. Further analyses demonstrate that the latent heat flux (the shortwave radiation) dominates the net heat flux in October (from November to February). The meridional temperature advection in the ocean is mostly due to the meridional Ekman convergence, which is related to the Aleutian low. Climatologically, the strengthening and southward migration of the Aleutian low from October to the following February are characterized by the acceleration and southward shift of the westerly wind to the south, respectively, which can drive southward ocean currents. Correspondingly, the southward ocean currents provide for colder meridional advection to the north of the NPSTF in January and February, favoring frontogenesis. In addition, the Aleutian low plays a role in transforming the dominant effect of the net heat flux into the joint effect of meridional temperature advection and net heat flux in January.
\end{abstract}




\section{Introduction}

The North Pacific Ocean is featured by two zonal sea surface temperature (SST) fronts at the midlatitudes and subtropics, respectively. The midlatitude front, with greater magnitude, is referred to as the North Pacific subarctic SST front (NPSAF), and the subtropical one is the North Pacific subtropical SST front (NPSTF). Due to the smaller magnitude, the NPSTF has been rarely studied. However, it also exerts significant influences on the overlying atmosphere (Xie, 2004; Kobashi et al., 2008; Wang et al., 2016; Zhang et al., 2017a, b). On the synoptic scale, Kobashi et al. (2008) found that the subsynoptic lows along the NPSTF are enhanced by condensational heating and baroclinicity associated with the NPSTF during April to May. On the interannual scale, the intensified NPSTF in spring can not only accelerate the East Asian westerly jet (Zhang et al., 2017a), but also serve as a precursor to the following La Niña event (Zhang et al., 2017b).

From the perspective of seasonal variation, the NPSAF can exist throughout the year, but the NPSTF is robust in winter and spring and is absent in summer and autumn (Fig. 1; Kobashi and Xie, 2012). Thus, several studies have focused on the frontogenesis and frontolysis of the NPSTF (Roden, 1975; Kazmin and Rienecker, 1996; Qiu and Kawamura, 2012). It is pointed out that the net heat flux is responsible for the frontolysis of the NPSTF (Qiu and Kawamura, 2012; Qiu et al., 2014). In terms of the frontogenesis, Roden (1975) found that meridional Ekman convergence is the primary reason for the frontogenesis of the NPSTF. However, Kazmin and Rienecker (1996) diagnosed the mixed-layer heat budget equation using observation data from 1982 to 1990 and pointed out that both the net heat flux and the Ekman convergence are frontogenetic and equally important to provide the observed frontogenesis in winter, rather than the Ekman convergence alone. This finding is further confirmed by Dinniman and Rienecker (1999) based on a 10-year (1985-1995) simulation of a primitive equation model (Geophysical Fluid Dynamics Laboratory's MOM2). However, they argued that these two factors are not equally important: the net heat flux (the Ekman convergence) dominates the frontogenesis in the western subtropical Pacific (the central and eastern subtropical Pacific). Thus, the relative role of the net heat flux and the Ekman convergence in the frontogenesis of the NPSTF remains unclear due to limited data used in previous studies. Meanwhile, the net heat flux is associated with the air-sea interaction, and the Ekman convergence is driven by the surface wind stress, implying that both frontogenesis factors are closely related to the atmospheric circulation. Kazmin (2017) demonstrated that the long-term (quasi-decadal) variability of the subtropical SST front is determined by the variability of the meridional shear of the zonal wind. Thus, the role of the atmosphere in the frontogenesis of the NPSTF deserves further study.
Therefore, this paper aims to figure out the relative importance of the net heat flux and the oceanic meridional temperature advection (including the Ekman convergence) in the frontogenesis of the NPSTF, especially the role of the atmosphere in this process. The rest of the paper is organized as follows. We introduce the data and methods in Sect. 2. We analyze the frontogenesis of the NPSTF using the mixedlayer heat budget equation in Sect. 3 to explore the relative importance of the net heat flux and the oceanic meridional temperature advection. Section 4 further investigates the role of the atmosphere in frontogenesis. A conclusion and discussion are given in Sect. 5.

\section{Data and methods}

\subsection{Data}

We use monthly ocean temperature, current velocities and wind stress from the Simple Ocean Data Assimilation (SODA; Carton and Giese, 2008) version 2.2.4 at $0.5^{\circ} \times 0.5^{\circ}$ grid resolution with 40 levels from the depth of 5 to $2000 \mathrm{~m}$. We also use surface heat fluxes from the Objectively Analyzed Air-sea Fluxes Project (OAFlux; Yu and Weller, 2007) at $2.5^{\circ} \times 2.5^{\circ}$ grid resolution to examine the mixed-layer heat budget. All heat fluxes are defined to be positive downward. For consistency, all variables are interpolated onto a $0.5^{\circ} \times 0.5^{\circ}$ grid, and they cover the period from January 1984 to December 2009 . The ocean temperature at $1.0^{\circ} \times 1.0^{\circ}$ grid resolution with 27 levels from the International Pacific Research Center (IPRC) Argo Product, together with ocean currents (on 40 levels) and surface heat fluxes at $0.3^{\circ} \times 1.0^{\circ}$ grid resolution from the NCEP Global Ocean Data Assimilation System (GODAS; Saha et al., 2006), is used to confirm our results based on the SODA data. The Argo and GODAS data are interpolated onto a $1.0^{\circ} \times 1.0^{\circ}$ grid at 27 depths and only cover the period from January 2005 to December 2013.

The atmospheric geopotential height and winds used in this study are monthly ERA-Interim reanalysis from the European Center for Medium-Range Weather Forecasts (ECMWF; Dee et al., 2011). They are on a $1.5^{\circ} \times 1.5^{\circ}$ grid and cover the period from January 1984 to December 2009.

\subsection{The mixed-layer heat budget equation}

The temporal variation of SST is governed by mixed-layer dynamics, which can be represented by the mixed-layer heat budget equation (Dinniman and Rienecker, 1999; Zhang et al., 2013):

$\frac{\partial \mathrm{SST}}{\partial t}=-u \frac{\partial \mathrm{SST}}{\partial x}-v \frac{\partial \mathrm{SST}}{\partial y}-w \frac{\Delta T}{H}+\frac{Q_{\mathrm{net}}}{\rho_{0} c_{p} H}+R$,

where SST denotes sea surface temperature (here, we assume that SST equals mixed-layer mean temperature), and $\Delta T$ represents the temperature difference between the mixed layer and the interior ocean immediately below the mixed 

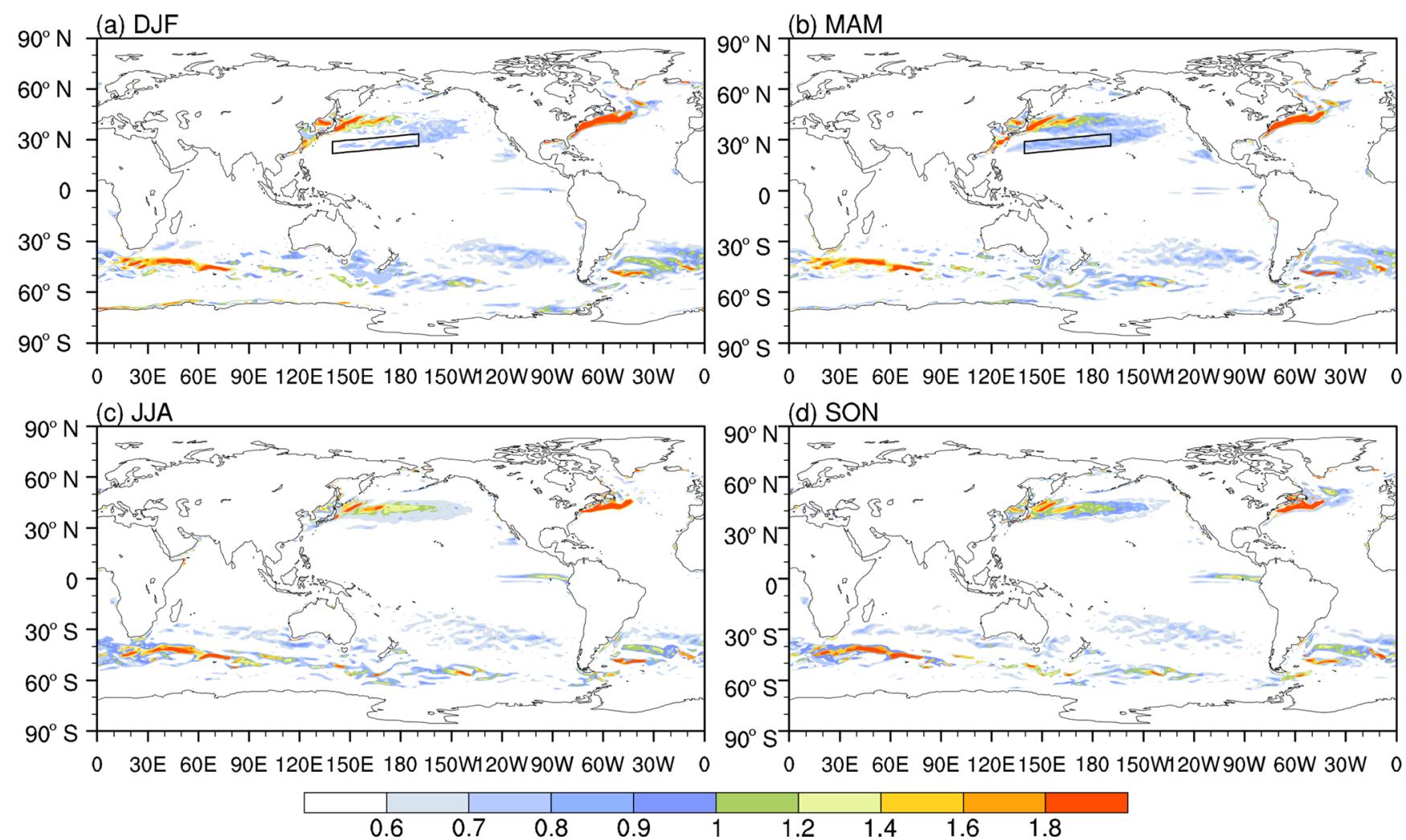

Figure 1. Climatological meridional SST gradients $\left(|\partial S S T / \partial y|\right.$, units: $\left.{ }^{\circ} \mathrm{C}(100 \mathrm{~km})^{-1}\right)$ in (a) winter, (b) spring, (c) summer and (d) autumn. Winter refers to the time period of December in the preceding year and January-February in the current year (DJF). The spring, summer and autumn refer to the time periods March-Apil-May (MAM), June-July-August (JJA) and September-October-November (SON), respectively. The black boxes in (a) and (b) indicate the key area of the NPSTF.

layer. $u$ and $v$ are mixed-layer zonal and meridional oceanic current velocities, respectively; $w$ is the vertical velocity at the bottom of the mixed layer. $H$ is mixed-layer depth. $Q_{\text {net }}$ is the net surface heat flux, including sensible and latent heat fluxes, as well as longwave and shortwave radiation. A positive value of $Q_{\text {net }}$ means that the ocean gains heat from the atmosphere. $\rho_{0}$ and $c_{p}$ are the density and heat capacity of seawater, respectively. $R$ is the residual term, including sub-grid-scale processes and dissipation. The zonal temperature advection $(-u \partial \mathrm{SST} / \partial y)$, meridional temperature advection $(-v \partial S S T / \partial y)$ and vertical temperature advection $(-w \Delta T / H)$ are intrinsic processes in the ocean (Yu and Boer, 2004; Chen et al., 2014), while the net heat flux term $\left(Q_{\text {net }} / \rho_{0} c_{p} H\right)$ represents air-sea interaction. The SST tendency $(\partial \mathrm{SST} / \partial t)$ in a particular month is obtained through the central finite difference.

Since the meridional gradient of SST overwhelmingly dominates over its zonal counterpart in the frontal region, the gradient magnitude (GM) of the NPSTF is defined as $\mathrm{GM}=-\partial \mathrm{SST} / \partial y$ to measure the intensity of the NPSTF in a particular month (Qiu and Kawamura, 2012; Qiu et al., 2014). Accordingly, GM is always positive because the climatological mean SST is higher in the south. Its tendency can be derived from Eq. (1) as follows:

$$
\begin{aligned}
\frac{\partial \mathrm{GM}}{\partial t} & =\frac{\partial}{\partial y}\left(u \frac{\partial \mathrm{SST}}{\partial x}\right)+\frac{\partial}{\partial y}\left(v \frac{\partial \mathrm{SST}}{\partial y}\right)+\frac{\partial}{\partial y}\left(w \frac{\Delta T}{H}\right) \\
& -\frac{\partial}{\partial y}\left(\frac{Q_{\text {net }}}{\rho_{0} c_{p} H}\right)-\frac{\partial R}{\partial y} .
\end{aligned}
$$

A bigger (smaller) GM indicates a stronger (weaker) NPSTF. A positive GM tendency $(\partial \mathrm{GM} / \partial t)$ suggests a process through which GM gradually increases, corresponding to the frontogenesis of the NPSTF. A negative GM tendency indicates the decreasing of GM, corresponding to the frontolysis of the NPSTF.

\subsection{Definition of the mixed-layer depth}

Three definitions of mixed-layer depth $H$ are used in this study: (a) SST $-T_{H}=0.5^{\circ} \mathrm{C}$ (Qiu et al., 2014), where $T_{H}$ is the temperature at the base of the mixed layer, and the depth of $0.5^{\circ} \mathrm{C}$ lower than the SST is defined as $H$. (b) SST $T_{H}=1.0^{\circ} \mathrm{C}$ (Suga and Hanawa, 1990), so the depth of $1.0^{\circ} \mathrm{C}$ lower than the SST is defined as $H$. (c) The mixedlayer depth is taken from the GODAS. Figure 2a shows the latitude-time section of the climatological mean mixed-layer 
(a) Mixed layer

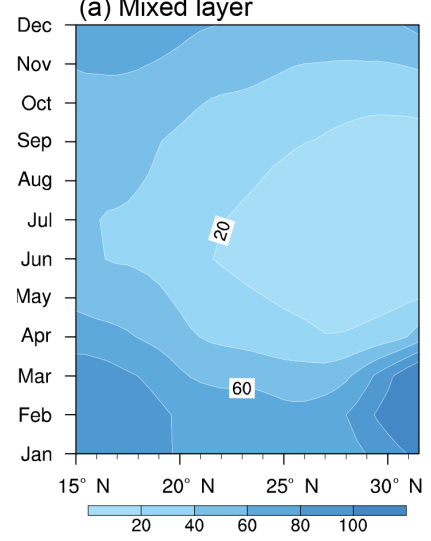

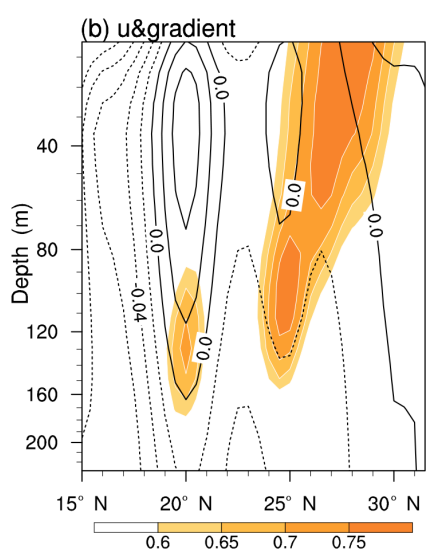

Figure 2. (a) Latitude-time section of the climatological monthly mean mixed-layer depth (units: meters) calculated by SST $-T_{H}=$ $0.5^{\circ} \mathrm{C}$. (b) Latitude-depth section of the climatological zonal current velocity (black contour; units: $\mathrm{ms}^{-1}$ ), superimposed with ocean temperature gradient (shading; units: $\left.{ }^{\circ} \mathrm{C}(100 \mathrm{~km})^{-1}\right)$; both are averaged over winter and spring. All three fields are averaged zonally over $140^{\circ} \mathrm{E}-170^{\circ} \mathrm{W}$.

depth calculated by method (a) averaged from $140^{\circ} \mathrm{E}$ to $170^{\circ} \mathrm{W}$ (longitudinal region of the NPSTF in Fig. 1; Zhang et al., 2017a). The mixed-layer depth exhibits significant seasonal variation, namely deep in winter and spring with a maximum of $60-80 \mathrm{~m}$ and shallow in summer with a minimum of $20 \mathrm{~m}$. Figure $2 \mathrm{~b}$ shows the latitude-depth section of the climatological mean zonal current velocities and ocean temperature gradients averaged in winter and spring when the NPSTF exists. The maximum center of the ocean temperature gradients (NPSTF) is mainly located between 24 and $30^{\circ} \mathrm{N}$ at the surface and could expand downward to the depth of $60 \mathrm{~m}$. The vertical scale of the maximum center is consistent with the deeper mixed layer in winter and spring calculated by method (a), suggesting that the variation of the mixed-layer-averaged temperature gradient can represent the variation of the NPSTF well. The mixed-layer depth is also computed by methods (b) and (c). Except for the deeper depth in winter and spring $(\sim 80 \mathrm{~m})$, their temporal evolutions of the mixed-layer depth agree well with that in Fig. 2a, and the diagnosis results of Eqs. (1) and (2) do not change qualitatively (not shown). Therefore, method (a) is used to define the mixed-layer depth in this study. In addition, two subsurface subtropical temperature fronts are located between 80 and $180 \mathrm{~m}$ in Fig. 2b, associated with the two branches of the North Pacific subtropical countercurrent, consistent with the findings of Kobashi et al. (2006). Note that the eastward velocities are relatively weak over 25$30^{\circ} \mathrm{N}$ where the ocean temperature gradients are strongest. This may be due to the offset of the salinity gradients, which yield westward zonal velocities there (not shown).

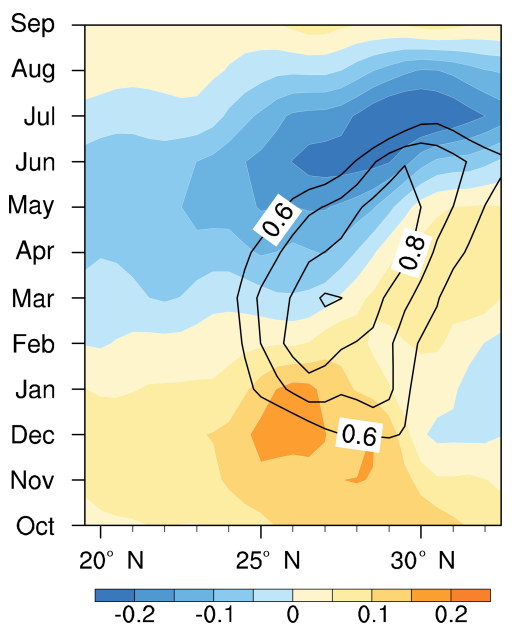

Figure 3. Latitude-time section of the climatological monthly mean gradient magnitude (GM) of the NPSTF (black contour; units: ${ }^{\circ} \mathrm{C}(100 \mathrm{~km})^{-1}$ ) and its tendency (shading; units: ${ }^{\circ} \mathrm{C}(100 \mathrm{~km})^{-1}$ month $\left.^{-1}\right)$, averaged zonally over $140^{\circ} \mathrm{E}-170^{\circ} \mathrm{W}$.

\section{Frontogenesis of the NPSTF}

Figure 3 shows latitude-time sections of the climatological mean GM and its tendency averaged over $140^{\circ} \mathrm{E}-$ $170^{\circ} \mathrm{W}$. The GM tendency is positive and moves southward from September to the following February. The NPSTF that forms in December is characterized by an SST gradient of $0.6^{\circ} \mathrm{C}(100 \mathrm{~km})^{-1}$, which is the threshold for the emergence and disappearance of the NPSTF according to Qiu et al. (2014). Then, it strengthens and slightly migrates southward until March, with a maximum of $0.9^{\circ} \mathrm{C}(100 \mathrm{~km})^{-1}$ at $27^{\circ} \mathrm{N}$. Although the NPSTF is still robust in spring, it exhibits an evident northward shift with a strengthening in the northern part and a weakening in the southern and central parts. It finally disappears in July, consistent with previous studies (Dinniman and Rienecker, 1999; Qiu et al., 2014). In this study, we mainly focus on the frontogenesis period of the NPSTF, which is from October to the following February when the GM tendency is significantly positive. As the NPSTF is located between 24 and $30^{\circ} \mathrm{N}$ during this period, the frontogenesis region of the NPSTF is defined as $140^{\circ} \mathrm{E}-$ $170^{\circ} \mathrm{W}, 24-30^{\circ} \mathrm{N}$.

\subsection{SST variation}

Since the NPSTF is characterized by the meridional gradient of SST in the subtropics, the SST variation during the frontogenesis of the NPSTF is the first thing we are interested in. Figure 4 portrays the temporal evolution of each term in Eq. (1) over the NPSTF from October to the following February. As shown in Fig. 4a, the SST tendency is coherently negative during frontogenesis, indicating that the SST across the NPSTF gradually decreases. Note that the SST decreases more quickly in the north than in the south, 


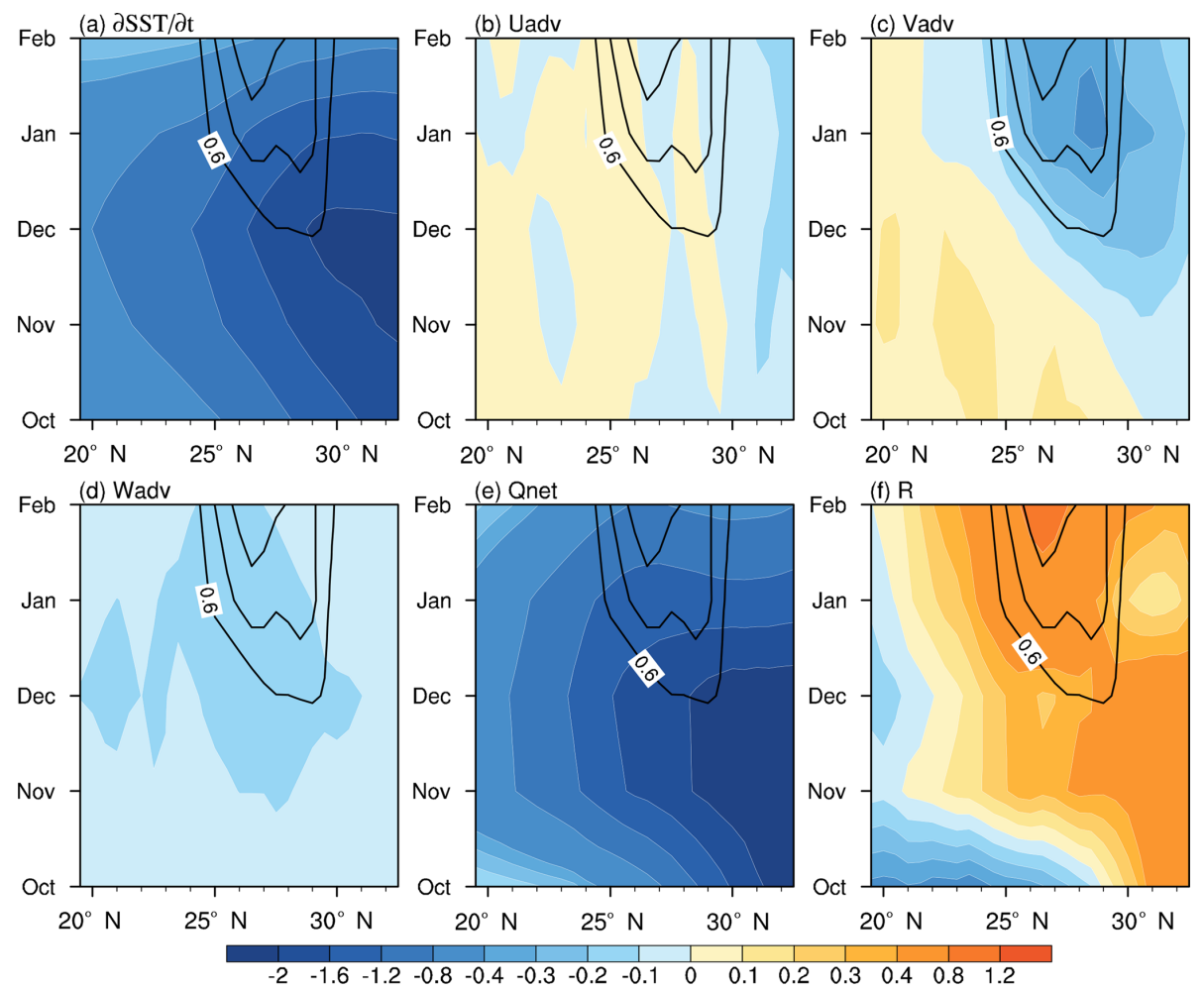

Figure 4. Latitude-time section of each term (shading; units: ${ }^{\circ} \mathrm{C}$ month ${ }^{-1}$ ) in Eq. (1) from October to the following February, averaged zonally over $\left(140^{\circ} \mathrm{E}-170^{\circ} \mathrm{W}\right)$. (a) The total SST tendency $(\partial \mathrm{SST} / \partial t)$ and (b-f) the components on the right-hand side of Eq. (1), namely zonal temperature advection $\left(U_{\mathrm{adv}}\right)$, meridional temperature advection $\left(V_{\mathrm{adv}}\right)$, vertical temperature advection $\left(W_{\mathrm{adv}}\right)$, the net heat flux $\left(Q_{\text {net }}\right)$ and the residual term $(R)$. The black contours in each panel are the same, indicating the climatological monthly mean $\mathrm{GM}\left(\mathrm{units}{ }^{\circ} \mathrm{C}(100 \mathrm{~km}){ }^{-1}\right)$ averaged zonally over $140^{\circ} \mathrm{E}-170^{\circ} \mathrm{W}$.

corresponding to the strengthening of the NPSTF. This indicates that the largely decreasing SST in the north should be the key for the frontogenesis of the NPSTF. A diagnosis of each contributor on the right-hand side of Eq. (1) is given in Fig. 4b-f. The SST tendency due to the net heat flux term (Fig. 4e) bears similarities to the SST tendency in Fig. $4 \mathrm{a}$ in terms of spatial pattern and magnitude, while the residual term $(R)$ is mainly positive and facilitates an increasing SST. As for the oceanic intrinsic processes, the meridional temperature advection serves as a much more important factor in determining the SST tendency compared to the zonal and vertical temperature advections, especially in January and February. In addition, the meridional temperature advection experiences a significant southward displacement, which slightly increases the SST across the NPSTF in October and November and strongly decreases the SST in January and February. This is similar to the southward migration of the GM tendency during frontogenesis (Fig. 3). Overall, the SST across the NPSTF gradually decreases during the frontogenesis, which is mainly attributed to the net heat flux term with some contributions from the cold meridional advection in January and February. The residual term acts to suppress this decreasing tendency.

\subsection{GM variation}

Figure 5a shows the temporal evolution of the climatological mean GM tendency across the NPSTF from October to the following February. It is positive and moves southward during the frontogenesis period, corresponding to the gradual enhancement of the NPSTF. Similar to the SST tendency from October to December (Fig. 4), the GM tendency is mainly caused by the net heat flux term (Fig. 5e), while the residual term acts to suppress the frontogenesis process (Fig. 5f). In January and February, the net heat flux term, together with the meridional temperature advection, favors the frontogenesis of the southern and central NPSTF and suppresses the frontogenesis of the northern NPSTF. The effect of $R$ is nearly the opposite. Note that the magnitude of the meridional temperature advection is quantitatively comparable to that of the net heat flux term in January and February. The zonal and vertical temperature advections are negligible due to their smaller magnitudes (Fig. $5 \mathrm{~b}$ and d). Figure 6a further shows the regionally averaged GM tendency across the NPSTF during frontogenesis. The net heat flux term dominates the GM tendency from October to December and decreases after January. The meridional temperature advection increases gradually from October to December and 

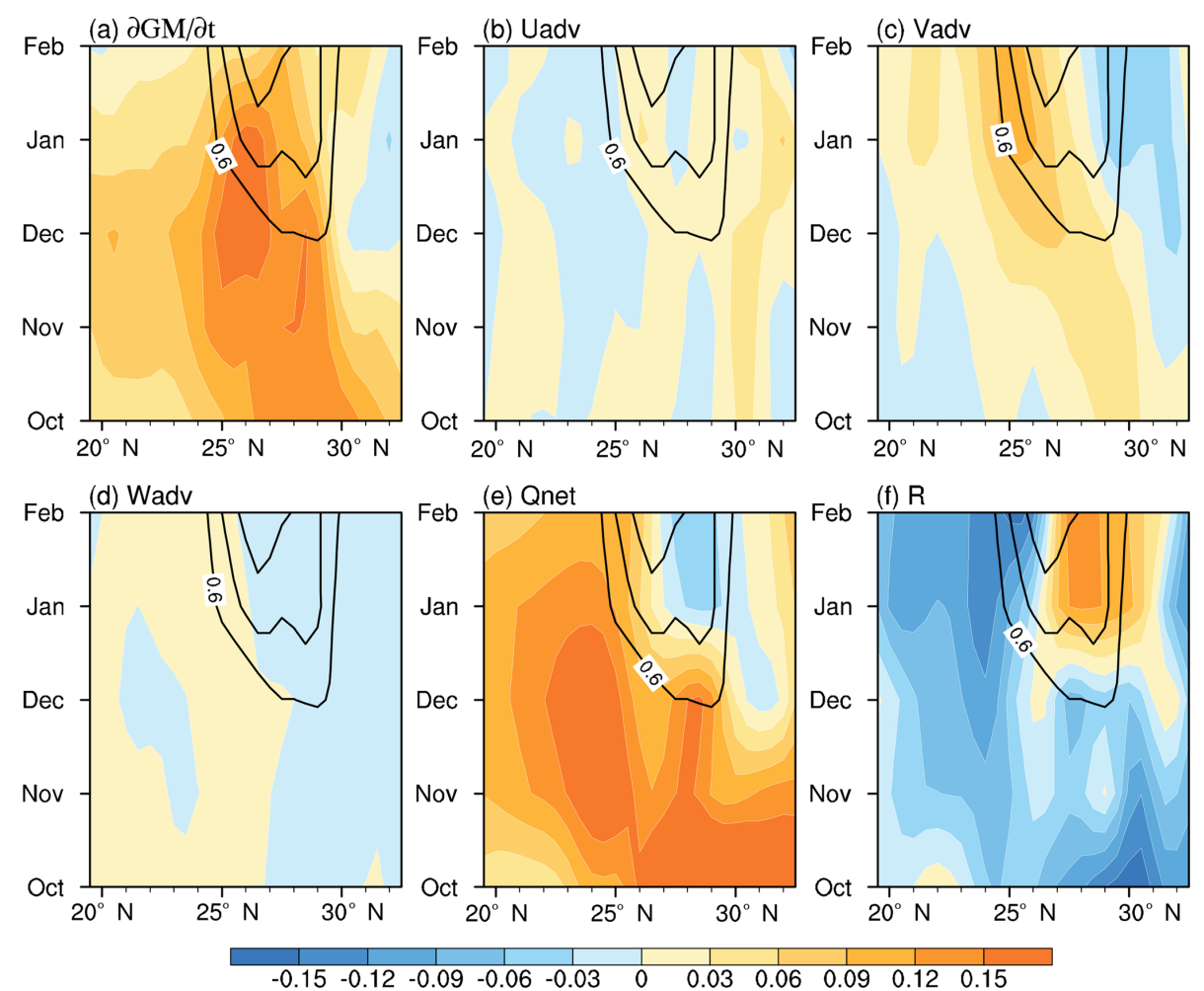

Figure 5. Same as Fig. 4, except for the terms (units: ${ }^{\circ} \mathrm{C}(100 \mathrm{~km})^{-1}$ month $\left.^{-1}\right)$ in Eq. (2).

plays an important role in January and February. The residual term $(R)$ mainly exerts an opposing influence on frontogenesis except in January. These findings can be quantitatively illustrated in Fig. 6b. The net heat flux term controls the NPSTF frontogenesis from October to December, while the meridional advection increases gradually and contributes equally as the net heat flux in January and February. The results in January and February are consistent with those in Kazmin and Rienecker (1996); namely, the net heat flux and the meridional Ekman convergence are equally important for frontogenesis in winter. In addition, the net heat flux also contributes to the disappearance of the NPSTF in summer (not shown), which is consistent with the finding of Qiu et al. (2014).

Figure $6 c$ shows the area mean GM tendency across the NPSTF calculated using Argo data from 2005 to 2013. Similar to Fig. 6a, the net heat flux term dominates from October to December and the meridional temperature advection works in January and February. However, the effect of the meridional temperature advection is overwhelmingly large in January and February, with a much smaller net heat flux term and $R$. This further confirms the dominant effect of the net heat flux term from October to December and the important role of the meridional temperature advection in January and February for the frontogenesis of the NPSTF. Therefore, similar to previous studies (Kazmin and Rienecker, 1996; Dinniman and Rienecker, 1999), both the net heat flux and oceanic meridional temperature advection contribute to the frontogenesis of the NPSTF. As for the relative importance, the net heat flux dominates frontogenesis from October to December and then the meridional temperature advection contributes equally as or even more than the net heat flux in January and February. In addition, although the magnitude of the net heat flux dominates the GM tendency from October to December, the variation of GM tendency is not all consistent with that of the net heat flux term, for example at $26.5^{\circ} \mathrm{N}$ (Fig. 5e). However, the increasing of the GM tendency corresponds to that of meridional temperature advection, highlighting the important role of the meridional temperature advection in frontogenesis.

\section{Roles of the atmosphere}

\subsection{Decomposition of the net heat flux}

The net heat flux term is critical for the frontogenesis of the NPSTF from October to December, which can be decomposed as follows:

$$
\frac{Q_{\mathrm{net}}}{\rho_{0} c_{p} H}=\frac{Q_{\mathrm{S}}}{\rho_{0} c_{p} H}+\frac{Q_{\mathrm{L}}}{\rho_{0} c_{p} H}+\frac{Q_{\mathrm{LR}}}{\rho_{0} c_{p} H}+\frac{Q_{\mathrm{SR}}}{\rho_{0} c_{p} H},
$$

where $Q_{\mathrm{S}}, Q_{\mathrm{L}}, Q_{\mathrm{LR}}$ and $Q_{\mathrm{SR}}$ represent sensible heat flux, latent heat flux, longwave radiation and shortwave radiation, respectively. Figure 7 shows the temporal evolution 

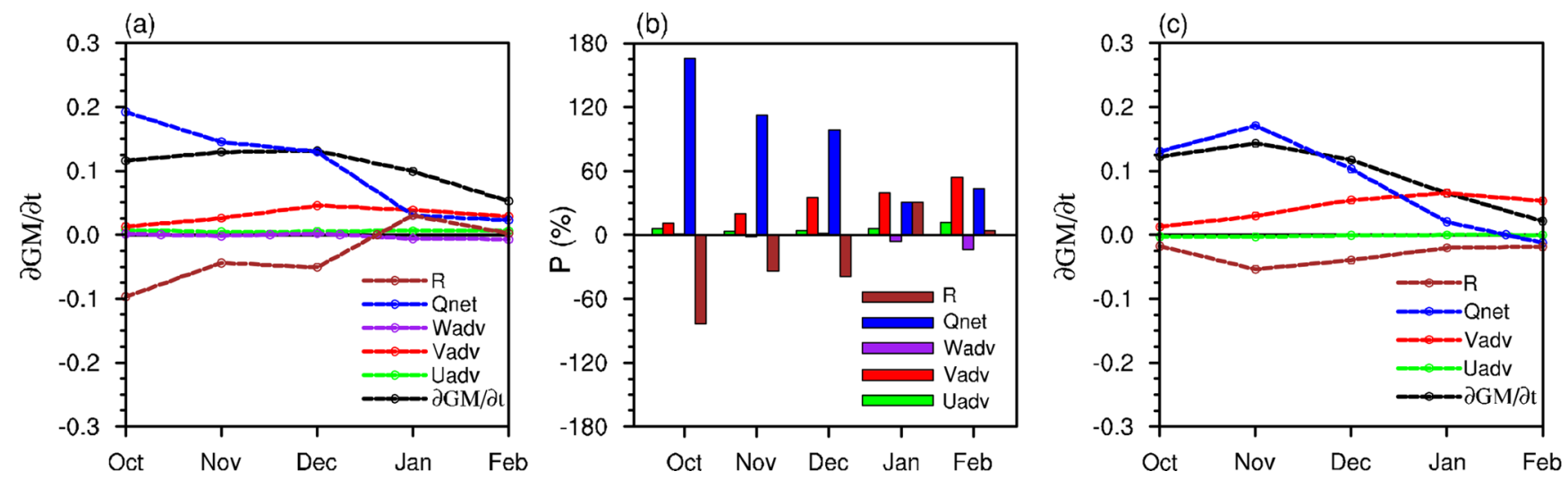

Figure 6. (a) The area mean GM tendency (units: ${ }^{\circ} \mathrm{C}(100 \mathrm{~km})^{-1}$ month $\left.^{-1}\right)$ over the NPSTF from October to the following February. (b) The contribution percentages of the right-hand-side terms in Eq. (2) to the left-hand-side term. (c) Same as Fig. 6a, except using the Argo data from 2005 to 2013. The black dashed line in (a) and (c) is the GM tendency of the NPSTF. Green, red, purple, blue and brown indicate zonal temperature advection $\left(U_{\mathrm{adv}}\right)$, meridional temperature advection $\left(V_{\mathrm{adv}}\right)$, vertical temperature advection $\left(W_{\mathrm{adv}}\right)$, the net heat flux $\left(Q_{\mathrm{net}}\right)$ and the residual term $(R)$, respectively.

of the GM tendency induced by individual heat flux terms in Eq. (3). The positive latent heat flux term primarily contributes to the positive GM tendency in October, together with the sensible heat flux and the longwave radiation terms. The shortwave radiation term evidently strengthens in November and December and appears to be the dominant factor in January and February. Meanwhile, the other three terms act to suppress frontogenesis, especially the latent heat flux term. Therefore, the four components of the net heat flux jointly contribute to the frontogenesis of the NPSTF, with a leading effect of the latent heat flux term in October and the shortwave radiation term from November to February. Note that the temporal variation of the net heat flux term is consistent with that of the latent heat flux term. Moreover, the quick decrease in the net heat flux term in January is mainly attributed to the reduction of the latent heat flux term.

\subsection{Cold meridional advection}

As discussed above, meridional temperature advection plays an important role in the frontogenesis of the NPSTF in January and February (Fig. 6), which transports cold water from the north to decrease the SST across the NPSTF. Figure 8 gives the meridional Ekman convergence of $\partial\left(V_{\mathrm{E}} \partial \mathrm{SST} / \partial y\right) / \partial y$ calculated by the meridional Ekman velocity $V_{\mathrm{E}}=-\tau_{x} / \rho_{0} f H$, where $\tau_{x}$ is the zonal component of wind stress and $f$ is the Coriolis parameter. The meridional Ekman convergence moves southward from October and strengthens in January and February, similar to the meridional temperature advection (Fig. 5c). In terms of magnitude, the Ekman convergence also largely contributes to the meridional temperature advection in frontogenesis. Thus, the meridional temperature advection in January and February is mostly due to the meridional Ekman convergence. Note that $\tau_{x}=c_{\mathrm{D}} \rho_{\mathrm{a}} U^{2}$, where $c_{\mathrm{D}}$ is the drag coefficient, $\rho_{\mathrm{a}}$ is air

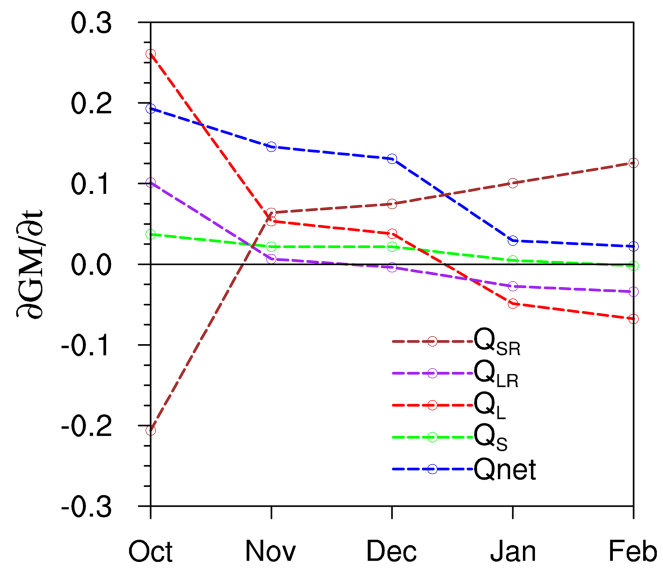

Figure 7. The contribution (units: $\left.{ }^{\circ} \mathrm{C}(100 \mathrm{~km})^{-1} \mathrm{month}^{-1}\right)$ of the net heat flux term and its individual component to the GM tendency over the NPSTF from October to the following February: the net heat flux term ( $Q_{\text {net }}$, blue), sensible heat flux term $\left(Q_{\mathrm{S}}\right.$, green), latent heat flux term $\left(Q_{\mathrm{L}}\right.$, red), longwave radiation term $\left(Q_{\mathrm{LR}}\right.$, purple) and shortwave radiation term $\left(Q_{\mathrm{SR}}\right.$, brown).

density and $U$ is the surface zonal wind speed. Accordingly, the meridional Ekman convergence must be associated with zonal wind speed. In the following, we focus on the possible atmospheric influence on the meridional temperature advection.

Figure 9a shows latitude-time sections of the climatological monthly mean geopotential height and zonal wind speed at $1000 \mathrm{hPa}$. The Aleutian low strengthens and heads southward from $\sim 48^{\circ} \mathrm{N}$ in October to $\sim 35^{\circ} \mathrm{N}$ in February, with the associated westerly wind enhanced and shifted southward. In theory, the westerly wind stress covaries with the westerly wind, which can force southward Ekman ocean currents in the Northern Hemisphere according to $V_{\mathrm{E}}=$ 


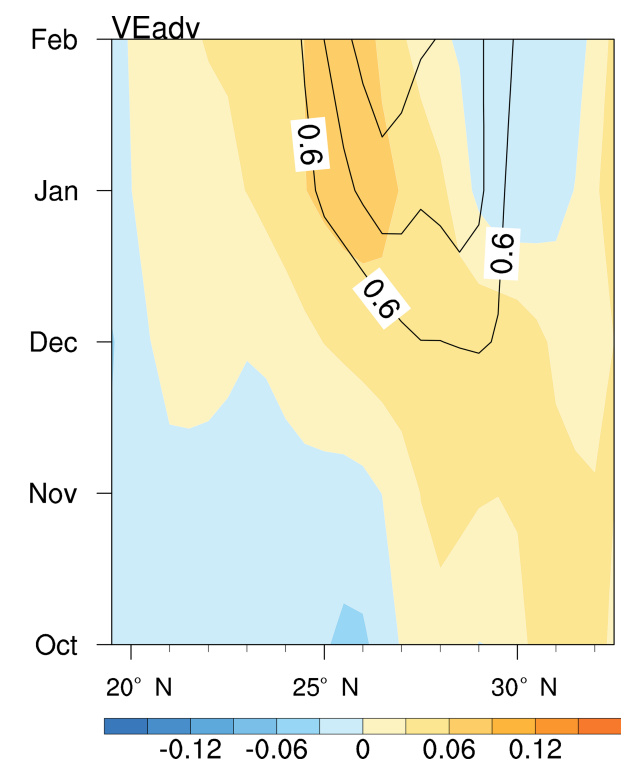

Figure 8. Same as Fig. 5c, except for the meridional temperature advection term calculated by the Ekman velocity.

$-\tau_{x} / \rho_{0} f H$. Thus, the southward meridional ocean currents are obviously increased and move southward from October to the following February with the Aleutian low (Fig. 9b). Correspondingly, the cold meridional advection is enhanced and moves southward, cooling the SST across the NPSTF in January and February, which is consistent with the southward migration of the meridional temperature advection in Fig. 4c. Li (2010) found that an Aleutian-low-like anomalous wind stress can decrease the SST in the midlatitude North Pacific (north of $25^{\circ} \mathrm{N}$ ) in numerical models. Further analysis revealed that cold meridional advection, induced by the Aleutian-low-like anomalous wind stress, acts to decrease the SST north of $25^{\circ} \mathrm{N}$. This previous study suggested that the strengthening and southward migration of the Aleutian low can decrease the SST across the NPSTF via the cold meridional advection. In addition, both the westerlies and the southward currents reach the southern latitude of $28^{\circ} \mathrm{N}$, resulting in colder SST in the northern NPSTF than in the southern NPSTF, corresponding to the frontogenesis of the NPSTF. The cooler SST in the north is also associated with the fact that northern SST cooling contributes greatly during frontogenesis (Fig. 4a). Thus, the meridional Ekman convergence dominates the cold meridional advection, which may be related to the strengthening and southward migration of the Aleutian low from October to the following February. The associated westerly wind, together with the wind-driven southward currents, is strengthened and shifts southward to induce cooler SST in the northern NPSTF, favoring its frontogenesis.

Note that the rapid decrease in the net heat flux term in January is mainly due to the reduction of the latent heat flux term. The latent heat flux term can be calculated by

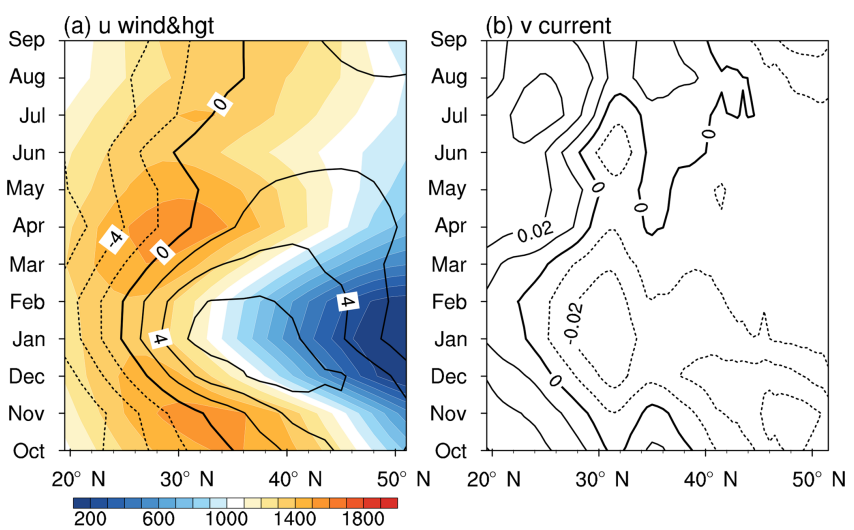

Figure 9. Latitude-time sections of (a) the climatological monthly mean geopotential height (shading; units: $\mathrm{m}^{2} \mathrm{~s}^{-2}$ ) and zonal wind speed at $1000 \mathrm{hPa}$ (black contour; units: $\mathrm{m} \mathrm{s}^{-1}$ ); (b) the climatological monthly mean meridional ocean currents (units: $\mathrm{m} \mathrm{s}^{-1}$ ). All variables are averaged zonally over $140^{\circ} \mathrm{E}-170^{\circ} \mathrm{W}$.

$Q_{\mathrm{L}}=\rho_{\mathrm{a}} L C U_{10 \mathrm{~m}}\left(q_{s}-q_{a}\right)$, where $L$ is the latent heat of vaporization, $C$ is the bulk coefficient, and $U_{10} \mathrm{~m}$ represents the $10 \mathrm{~m}$ wind speed (Qiu et al., 2014). According to Eq. (2), the GM tendency is proportional to the meridional gradient of the $10 \mathrm{~m}$ wind speed $\left(-\partial U_{10} \mathrm{~m} / \partial y\right)$. Figure 10 shows the temporal evolutions of $-\partial U_{10 \mathrm{~m}} / \partial y$ across the NPSTF and GM tendency associated with the latent heat flux term. The meridional gradient of wind speed gradually decreases from October to the following February, consistent with the GM tendency calculated by the latent heat flux term, especially from December to February. Interestingly, the decreasing $-\partial U_{10 \mathrm{~m}} / \partial y$ is also consistent with the southward migration of the Aleutian low (blue line in Fig. 10). This southward shift leads to a gradual increase in the wind speed to the south of the Aleutian low (to the north of the NPSTF), corresponding to the decrease in $-\partial U_{10 \mathrm{~m}} / \partial y$ between the NPSTF and its northern region, further resulting in the decease in the latent heat flux term during the frontogenesis. Therefore, the Aleutian low acts to decrease the effect of the net heat flux and to increase the effect of the meridional temperature advection during the frontogenesis, which may also play an important role in transforming the dominant effect of the net heat flux into the joint effect of meridional temperature advection and net heat flux in January.

\section{Conclusion and discussion}

Previous studies have demonstrated that both net heat flux and meridional temperature advection in the ocean contribute to NPSTF frontogenesis (Kazmin and Rienecker, 1996; Dinniman and Rienecker, 1999). However, the relative importance of these two factors in frontogenesis is not stated clearly. In this study, we investigated the frontogenesis of the NPSTF occurring from October to the following February based on the mixed-layer heat budget equation and fur- 


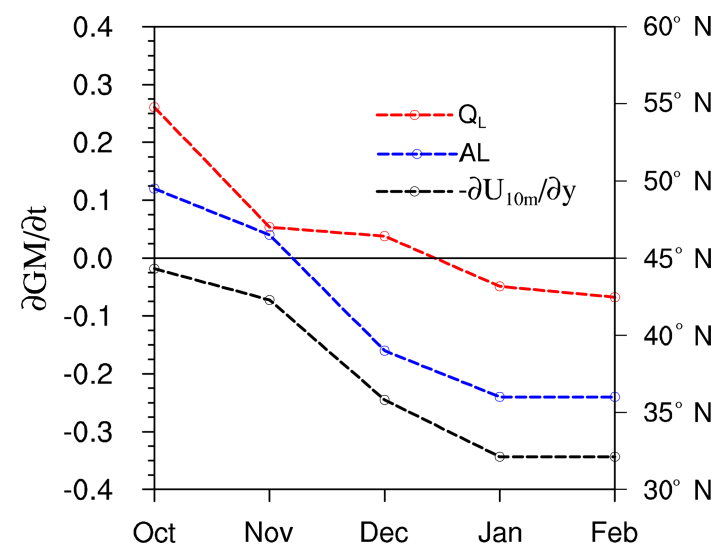

Figure 10. Meridional gradient of $10 \mathrm{~m}$ wind speed $\left(-\partial U_{10 \mathrm{~m}} / \partial y\right.$, black, units: $\left.10^{-5} \mathrm{~s}^{-1}\right)$ and GM tendency calculated by the latent heat flux $\left(Q_{\mathrm{L}}\right.$, red, units: $\left.{ }^{\circ} \mathrm{C}(100 \mathrm{~km})^{-1} \mathrm{month}^{-1}\right)$ over the NPSTF. The blue curve (AL) is the latitude of climatological geopotential height at $900 \mathrm{~m}^{2} \mathrm{~s}^{-2}$ averaged zonally over $140^{\circ} \mathrm{E}-170^{\circ} \mathrm{W}$, representing the southward migration of the Aleutian low.

ther find that the net heat flux and meridional temperature advection play different roles in the different periods of frontogenesis. The net heat flux dominates the frontogenesis of the NPSTF from October to December, while the meridional temperature advection contributes equally as or even more than the net heat flux in January and February. The zonal and vertical temperature advections can be neglected due to their smaller magnitudes, while $R$ acts to suppress frontogenesis except in January.

Moreover, the role of the atmosphere in frontogenesis is also explored, including the direct effect of the net heat flux and the indirect effect through the Aleutian low. A decomposition of the net heat flux term reveals that its four components jointly contribute to frontogenesis, with a leading role by the latent heat flux in October and by shortwave radiation from November to the following February. Further analyses of atmospheric effects on the oceanic process show that the meridional Ekman convergence dominates the meridional temperature advection and is associated with Aleutian low variation. The strengthening and southward migration of the Aleutian low are characterized by the acceleration and southward shift of the westerly wind to the south, which benefits southward ocean currents. Accordingly, the cold meridional advection due to the southward currents induces cooler SST in the northern NPSTF than in the southern NPSTF and favors the frontogenesis of the NPSTF in January and February. In addition, the reduction of the latent heat flux term (dominating the net heat flux term variation) during frontogenesis also results from the southward shift of the Aleutian low, suggesting that the Aleutian low also plays a role in transforming the dominant effect of the net heat flux into the joint contributions of meridional temperature advection and net heat flux in January.
Note that the residual term, including the sub-grid-scale process, is relatively large in our results, which may be due to the eddy-induced heat fluxes. Wunsch (1999) noted that eddy-induced heat fluxes are important relative to the total meridional heat fluxes in western boundary current regions of the North Atlantic and Pacific Ocean. Moreover, Qiu and Chen (2005) showed that the meridional eddy-induced heat fluxes over the subtropical North Pacific are both poleward for warm-core and cold-core eddies. Accordingly, poleward eddy-induced heat fluxes tend to transport warm water from lower latitudes to the subtropics and benefit the warmer water there. These findings are consistent with our result that the residual term leads to increasing SST over the NPSTF. Thus, the eddy-induced heat flux may play an important role in the residual term to increase the SST and to further halt frontogenesis (Figs. 4f and 5f). However, it is still hard to confirm this process at this stage because the spatial and temporal resolutions of the observations and reanalysis data used in study are relatively coarse. Thus, further exploration is needed when finer data become available to us.

Data availability. The SODA data are from http: //apdrc.soest.hawaii.edu/las/v6/dataset?catitem=4865 (last access: 17 April 2019, Carton and Giese, 2008). The Argo data are from http://apdrc.soest.hawaii.edu/las/v6/dataset?catitem=194 (last access: 17 April 2019, Li et al., 2017). The GODAS data are from https://www.esrl.noaa.gov/psd/data/gridded/data.godas.html (last access: 17 April 2019, Saha et al., 2006). The OAFlux data are from ftp://ftp.whoi.edu/pub/science/oaflux/data_v3/ monthly/radiation_1983-2009/ (last access: 17 April 2019 , $\mathrm{Yu}$ and Weller, 2007), and the ERA-Interim data are from http://apps.ecmwf.int/datasets/data/interim-full-moda/levtype $=$ sfc/ (last access: 17 April 2019, Dee et al., 2011).

Author contributions. LZ designed the study, analyzed the data and wrote the manuscript. HX initiated the idea and designed the study. JM, NS and JD contributed to the study design and writing of the manuscript.

Competing interests. The authors declare that they have no conflict of interest.

Acknowledgements. This work was jointly supported by the National Science Foundation of China (grant nos. 41575077, 41490643, 41575057, 41705054 and 41805051) and the National Key Research and Development Program of China (2017YFA0604102). Leying Zhang was supported by the scientific research start-up funds of Nanjing Forestry University (grant no. 163108056). Jiechun Deng was supported by the General Program of Natural Science Research of Jiangsu Province University (grant no. 17KJB170012) and the China Scholarship Council (grant no. 201808320137). 
Review statement. This paper was edited by Anders Levermann and reviewed by two anonymous referees.

\section{References}

Carton, J. A. and Giese, B. S.: A reanalysis of Ocean Climate Using Simple Ocean Data Assimilation, Mon. Weather Rev., 136, 2999-3017, https://doi.org/10.1175/2007MWR1978.1, 2008.

Chen, S. F., Yu, B., and Chen, W.: An analysis on the physical process of the influence of AO on ENSO, Clim. Dynam., 42, 973989, https://doi.org/10.1007/s00382-012-1654-z, 2014.

Dee, D. P., Uppala, S. M., and Simmons, A. J.: The ERAinterim reanalysis: configuration and performance of the data assimilation system, Q. J. Roy. Meteor. Soc., 137, 553-597, https://doi.org/10.1002/qj.828, 2011.

Dinniman, M. S. and Rienecker, M. M.: Frontogenesis in the North Pacific oceanic frontal zones: a numerical simulation, J. Phys. Oceanogr., 29, 537-559, https://doi.org/10.1175/15200485(1999)029<0537:FITNPO>2.0.CO;2, 1999.

Kazmin, A. S.: Variability of the climatic oceanic frontal zones and its connection with the large-scale atmospheric forcing, Prog. Oceanogr., 154, 38-48, https://doi.org/10.1016/j.pocean.2017.04.012, 2017.

Kazmin, A. S. and Rienecker, M. M.: Variability and frontogenesis in the large-scale oceanic frontal zones, J. Geophys. Res., 101, 907-921, https://doi.org/10.1029/95JC02992, 1996.

Kobashi, F. and Xie, S. P.: Interannual variability of the North Pacific subtropical countercurrent: Role of local ocean-atmosphere interaction, J. Oceanogr., 68, 113-126, https://doi.org/10.1007/s10872-011-0048-x, 2012.

Kobashi, F., Mitsudera, H., and Xie, S. P.: Three subtropical fronts in the North Pacific: Observation evidence for mode waterinduced subsurface frontogenesis, J. Geophys. Res.-Oceans, 111, 616-627, https://doi.org/10.1029/2006JC003479, 2006.

Kobashi, F., Xie, S. P., Iwasaka, N., and Sakamoto T. T.: Deep atmospheric response to the North Pacific oceanic subtropical front in spring, J. Climate, 21, 5960-5975, https://doi.org/10.1175/2008JCLI2311.1, 2008.

Li, C.: Variation of wind-driven oceanic gyre in the North Pacific and its feedback to atmospheric circulation, Ocean University of China, Qingdao, 2010 (in Chinese).

Li, H., Xu, F. H., Zhou, W., Wang, D. X., Wright, J. S., Liu, Z. H., and Lin, Y. L.: Development of a global gridded Argo data set with Barnes successive corrections, J. Geophys. Res., 122, 866889, https://doi.org/10.1002/2016JC012285, 2017.

Qiu, B. and Chen Q. M.: Eddy-induced heat transport in the subtropical North Pacific from Agro, TMI, and Altimetry Measurements, J. Phys. Oceanogr., 35, 458-473, https://doi.org/10.1175/JPO2696.1, 2005.
Qiu, C. and Kawamura, H.: Study on SST front disappearance in the subtropical North Pacific using microwave SSTs, J. Oceanogr., 68, 417-426, https://doi.org/10.1007/s10872-012-0106-z, 2012.

Qiu, C. H., Kawamura, H., Mao, H. B., and Wu, J.: Mechanisms of the disappearance of sea surface temperature fronts in the subtropical North Pacific Ocean, J. Geophys. Res.-Oceans, 119, 4389-4398, https://doi.org/10.1002/2014JC010142, 2014.

Roden, G. I.: On North Pacific Temperature, Salinity, Sound Velocity and Density Frontsand their Relation to the Wind and Energy Flux Fields, J. Phys. Oceanogr., 5, 557-571, https://doi.org/10.1175/15200485(1975)005<0557:ONPTSS>2.0.CO;2, 1975.

Saha, S., Nadiga, S., Thiaw, C., Wang, J., Wang, W., Zhang, Q., van den Dool, H. M., Pan, H. L., Moorthi, S., Behringer, D., Stokes, D., Pena, M., Lord, S., White, G., Ebisuzaki, W., Peng, P., and Xie, P.: The NCEP Climate Forecast System, J. Climate, 19, 3483-3517, https://doi.org/10.1175/JCLI3812.1, 2006.

Suga, T. and Hanawa, H.: The mixed-layer climatology in the northwestern part of the north Pacific subtropical gyre and the formation area of subtropical mode water, J. Mar. Res., 48, 543-566, https://doi.org/10.1357/002224090784984669, 1990.

Wang, L. Y., Hu, H. B., Yang, X. Q., and Ren, X. J.: Atmospheric eddy anomalies associated with the wintertime North Pacific subtropical front strength and their influence on the seasonal-mean atmosphere, Science Chinese Earth Sciences, 59, 2022-2036, https://doi.org/10.1007/s11430-016-5331-7, 2016.

Wunsch, C.: Where do ocean eddy heat fluxes matters?, J. Geophys. Res., 104, 13235-13249, https://doi.org/10.1029/1999JC900062, 1999.

Xie, S. P.: Satellite observations of cool ocean-atmosphere interaction, B. Am. Meteorol. Soc., 85, 195-208, https://doi.org/10.1175/BAMS-85-2-195, 2004.

$\mathrm{Yu}$, B. and Boer, G. J.: The role of the western Pacific in decadal variability, Geophys. Res. Lett., 31, L02204, https://doi.org/10.1029/2003GL018471, 2004.

Yu, L. and Weller, R. A.: Objectively Analyzed air-sea heat Fluxes for the global ice-free oceans (1981-2005), B. Am. Meteorol. Soc., 88, 527-539, https://doi.org/10.1175/BAMS-88-4-527, 2007.

Zhang, L. Y., Xu, H. M., Shi, N., and Deng, J. C.: Responses of the East Asian Jet Stream to the North Pacific Subtropical Front in spring, Adv. Atmos. Sci., 34, 144-156, https://doi.org/10.1007/s00376-016-6026-x, 2017a.

Zhang, L. Y., Xu, H. M., Shi, N., and Ma, J.: Impact of the North Pacific subtropical sea surface temperature front on El Niño-Southern Oscillation, Int. J. Climatol., 38, e729-e740, https://doi.org/10.1002/joc.5402, 2017b.

Zhang, W. J., Jin, F. F., Zhao, J. X., and Li, J.: On the bias in simulated ENSO SSTA meridional widths of CMIP3 models, J. Climate, 26, 3171-3186, https://doi.org/10.1175/JCLI-D-12$00347.1,2013$. 